\title{
PSEUDO-EPITHELIOMATOUS HYPERPLASIA OF CORNEA, CONJUNCTIVA, AND EYELID*
}

\author{
BY \\ ALY MORTADA \\ Department of Ophthalmology, Faculty of Medicine, Cairo University, Egypt
}

IN each of the three cases described below there was no important past or family history. A general examination revealed no abnormality, the lungs, heart, spleen, liver were normal, there was no enlargement of pre-auricular, submaxillary, cervical, or other lymph glands, and no other tumours in the body. The blood pressure, temperature, urine, faeces, and blood count were normal, the Wassermann reaction negative, and the tuberculin reaction positive. There were no signs of vitamin deficiency. Neither eyes nor lids were exposed to dust, injury, irradiation, excessive sun, tar, or arsenic. There was no skin pigmentation. The lids showed no excrescences of seborrhoeic keratosis, scales of senile keratosis, eczema, lupus vulgaris, or scars. The conjunctiva showed healed trachoma, but the cornea did not show trachomatous keratitis. Conjunctival smears were negative for organisms. The patients did not wear spectacles.

\section{Case Reports}

Case 1, a 54-year-old clerk, complained of diminution of vision of the right eye of 6 months' duration.

Examination.-The left eyelids, conjunctiva, cornea, and fundus were normal. The visual acuity was $6 / 9$.

The right eyelids were normal. The cornea and $2 \mathrm{~mm}$. of the bulbar conjunctiva around the limbus were covered by a flat mass with a cauliflower-like surface (Fig. 1), whitish, slightly firm, $3 \mathrm{~mm}$. high, $1.5 \mathrm{~cm}$. in diameter, non-pedunculated, not ulcerated, and with a distinct but somewhat irregular edge. The visual acuity was hand movements.

FIG. 1.-Case 1, pseudo-epitheliomatous hyperplasia of the cornea in a man aged 54 . Note whitish cauliflower-like surface of lesion.

\footnotetext{
* Received for publication March 24, 1961.
} 
Case 2, a 58-year-old butcher, complained of a left limbal swelling and lacrimation of 4 months' duration.

Examination.-The right eye was normal and the fundus normal, with visual acuity 6/12.

The left eyelids were normal. On the temporal side of the limbus a white, irregular, slightly firm mass $3 \mathrm{~mm}$. high extended onto the bulbar conjuctiva for $1 \mathrm{sq}$. $\mathrm{cm}$. and on the cornea for $2 \times 3 \mathrm{~mm}$. Slit-lamp examination showed the surface of the mass to be granular surrounded by vascular conjunctiva.

Case 3, a 60-year-old tailor, complained of a swelling of the right lower lid of 5 months' duration.

Examination.-The left eye and lids were normal, and the fundus normal, with visual acuity $6 / 9$.

The right upper lid and eye were normal, and the fundus normal, with visual acuity 6/9. In the medial part of the lower lid near the lid margin and below the lower lacrimal punctum there was a slightly firm mass $0.5 \mathrm{~cm}$. in diameter and $1 \mathrm{~cm}$. high. Its lower part was covered by skin continuous with the healthy skin around. In its upper part the covering skin was darker in colour with a dimple at the apex.

In each case, the superficial three-quarters of the lesion, and a small piece of the peripheral deep part with its attached corium were excised for biopsy. Histopathological examination showed hyperplasia, disarrangement of epithelial cells, and the poikilokarynosis of Darier(1914-15), comprising irregularity in size and shape and staining properties of the epithelial cells. Some mitotic figures were present. Most of the cells were large, and usually vacuolated, and each contained a large nucleus. Some prickle cells showed the early formation of keratohyaline. Serial sections showed normal palisaded basal epithelial cells and absence of epithelial cell invasion of the corium; the superficial layers of the corium showed mononuclear cell infiltration. There were no epithelial inclusions.

One week later, the deeper part of the lesion disappeared spontaneously in each case; the cornea in Case 1 became clear again (Fig. 2) and the visual acuity improved to $6 / 24$.

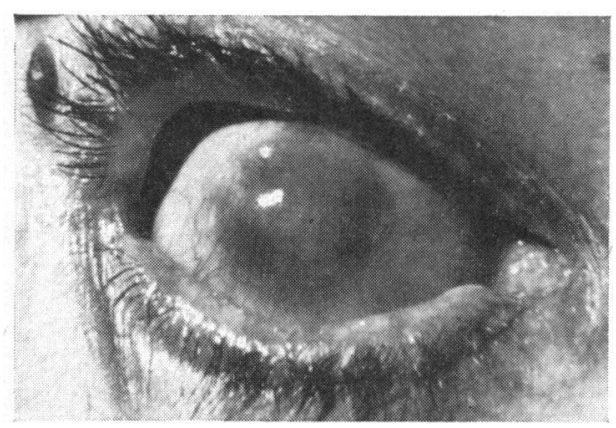

Fig. 2.-Case 1, clear cornea one week after incomplete excision of corneal pseudoepitheliomatous hyperplasia.

The lesions were diagnosed as pseudo-epitheliomatous hyperplasia of the cornea, limbus, and lid. The patients have each been observed for 2 years without evidence of recurrence. Tissue culture of the lesion on the chorio-allantoic membrane of chicken embryo was negative for viruses, and inoculation of the lesion emulsion to scarified lid epidermis and corneal epithelium of blind eyes of human volunteers did not reproduce any lesion during one year's observation. 


\section{Discussion}

Although in the three cases described a virus origin was not proved, yet the lesion resembled that seen in cases of filiform warts, molluscum contagiosum nodules of the skin, and conjunctival verrucae of virus origin, in which excision of the superficial three-quarters of the lesion usually leads to the disappearance of the rest.

\section{Summary}

Skin and conjunctival and corneal lesions, characterized histopathologically not only by epidermalization (in cases of conjunctiva and cornea), hyperkeratosis, parakeratosis, and acanthosis, but essentially by disarrangement, variations in size and shape of epithelial cells, presence of mitotic figures, appearance of keratohyaline, and even cell nests at the level of prickle cell layer with an intact palisaded basal cell layer, may be due either to precancerous neoplasm with malignant possibilities, or to pseudo-epitheliomatous hyperplasia probably of inflammatory origin.

This classification is of importance in considering the aetiology, diagnosis, prognosis, and treatment of such lesions. The two types can be differentiated by excising the superficial three-quarters of the lesion. Spontaneous disappearance of the rest of the mass in a few days points to the diagnosis of pseudo-epitheliomatous hyperplasia. Persistence and recurrence of the tumour point to the diagnosis of a true neoplasm. Many of the recorded intra-epithelial epitheliomata (Bowen's disease: Bowen, 1912) of the cornea, conjunctiva, and lid cured by local excision or radiation were probably of the pseudo-epitheliomatous type.

\section{REFERENCES}

BOWEN, J. T. (1912). J. cutan. Dis., 30, 241.

Darier, J. (1914-15). Ann. Derm. Syph., 5e sér., 5, 449. 